\title{
A GESTÃO ESCOLAR E A FORMAÇÃO DOCENTE: UM ESTUDO EM ESCOLAS DE UM MUNICÍPIO PAULISTA
}

\author{
GESTIÓN ESVOLAR Y FORMACIÓN DOCENTE: UN ESTUDIO EN ESCUELAS \\ DE UN MUNICIPIO PAULISTA
}

\author{
SCHOOL MANAGEMENT AND TEACHER EDUCATION: A STUDY IN \\ SCHOOLS OF THE ONE PAULISTA MUNICIPALITY
}

\author{
Paulo Sergio GARCIA ${ }^{1}$ \\ Nonato Assis de MIRANDA ${ }^{2}$
}

\begin{abstract}
RESUMO: A gestão escolar é responsável pela organização da escola, pelo desenvolvimento dos processos pedagógicos e financeiros, pela articulação e mobilização das pessoas e também pela formação de professores. Este estudo analisou como a gestão escolar de escolas públicas de ensino fundamental, anos finais, idealiza e realiza esta formação docente. Foi utilizada para a coleta de dados a etnografia escolar, com o pesquisador inserido no contexto escolar, realizando observações a partir de protocolos, entrevistas e análise documental. Os resultados mostraram que as escolas possuíam uma gestão da formação ainda "selvagem", marcada pela ausência de planejamento, de organização e de sistematização de objetivos e de compromissos com o desenvolvimento profissional docente. Tais questões eram decorrentes do fato de a gestão escolar não se sentir integralmente responsável pela formação dos professores e pela falta de formação dos gestores escolares. Esses dados podem ser utilizados no contexto da formação de diretores e coordenadores pedagógicos e ser utilizado como discussão nos departamentos de Educação.
\end{abstract}

PALAVRAS-CHAVE: Gestão escolar. Formação de professores. Ensino fundamental.

RESUMEN: A gestión escolar es responsable de la organización de la escuela, de lo desarrollo del los procesos pedagógicos y financieros, de la articulación y movilización de las personas y los maestros. Este estudio examinó como la gestión escolar de escuelas primarias públicas, años finales, idealiza y lleva a cabo la formación del profesorado. Se utilizo para recoger los datos la etnografía escolar, con el investigador trabajando en las escuelas, haciendo observaciones con el uso de protocolos, entrevistas y análisis de documentos. Los resultados mostraron que las escuelas tenían uma gestión de la formación que sigue siendo "salvajes", marcado por la ausencia de

\footnotetext{
${ }^{1}$ Universidade Municipal de São Caetano do Sul (USCS), São Caetano do Sul - SP - Brasil. Professor do departamento de Educação, dos cursos de mestrado e doutorado. Coordenador do Observatório de Educação do Grande ABC. E-mail: garciaps@usp.br.

${ }^{2}$ Universidade Municipal de São Caetano do Sul (USCS), São Caetano do Sul - SP - Brasil. Professor do departamento de Educação e dos cursos de mestrado. Coordenador do curso de Pedagogia. E-mail: mirandanonato@uscs.edu.br.
}

RIAEE - Revista Ibero-Americana de Estudos em Educação, Araraquara, v.12, n.4, p. 2210-2230, out./dez. 2017. 
planificación, organización y sistematización de los objetivos y el compromiso con el desarrollo profesional de los maestros. Esto se debió al hecho de que la gestión no se sientía plenamente responsable de la formación de profesores y la falta de formación de los directivos de la escuela. Estos datos pueden ser utilizados en la formación de los directores y coordinadores y ser usado como una discusión en el departamento de Educación.

PALABRAS CLAVE: Gestión escolar. Formación de profesores. Escuela primaria.

ABSTRACT: School management is responsible for the school organization, for the development of pedagogical and financial processes, for the articulation and mobilization of people and for teacher education. This study analyzed how the school management of public elementary schools (students from 11 to 14 years old), plan and accomplish teacher education in the school context. School ethnography was used for the data collection, with the researcher inserted in the school context, making observations via protocols, using interviews and documentary analysis. The results showed that the schools had a management of teacher education still "wild", marked by the absence of planning, organization and systematization of objectives and commitments to professional teacher development. These questions were stem from the fact that school management does not feel fully responsible for teacher education, and for the lack of school managers' education. These data can be used in the context of principals (and pedagogical coordinators) education, and used as a discussion in the departments of Education.

KEYWORDS: School management. Teacher training. Elementary school.

\section{Introdução}

Vários pesquisadores já sinalizaram que a escola é o local mais adequado para a formação do professor. Trata-se de uma formação que favorece, entre outras coisas, a colaboração, a criação de vínculos, o diálogo sobre as práticas, os interesses, as necessidades e o desenvolvimento da identidade do professor (CANÁRIO, 1998; FUSARI, 2009; GARCIA, 2010; CUNHA; PRADO, 2010). Uma formação pautada na responsabilidade social, na transformação e melhoria das práticas profissionais, na mudança escolar e na melhoria da aprendizagem do aluno.

Neste sentido, a Gestão Escolar (GE) que realiza, entre outras coisas, a organização e a gestão de pessoas, o gerenciamento administrativo e pedagógico, a mobilização da cultura escolar e dos resultados educacionais (LÜCK, 2009), tem de se interessar e organizar, idealizar e realizar, a formação dos professores no contexto escolar. 
No cenário brasileiro, no entanto, a GE tem sido mais atuante nos aspectos administrativos do que pedagógicos (PARO, 2011). Para Libâneo; Oliveira; Toschi (2007), na maioria de nossas escolas, ainda prevalece a concepção técnico-científica de gestão a partir da qual perdura uma visão burocrática e tecnicista de escola. Neste caso, a direção fica situada sobre uma ou duas pessoas, com decisões verticais, baseada em uma realidade objetiva e neutra, focando em aspectos de eficiência e eficácia e em resultados nos moldes da administração gerencial (PARENTE, 2016; RAMOS, 2016), perdendo-se de referência, portanto, o entendimento de que a gestão "[...] não se ocupa do esforço despendido por pessoas isoladamente, mas com o esforço humano coletivo" (PARO, 2012, p.31).

Pesquisadores que vislumbram a escola como uma organização aprendente (FULLAN, 2000), ou como comunidades de aprendizagem (DUFOUR; MARZANO, 2009; DUFOUR; FULLAN 2013; FULLAN, 2010; LEITHWOOD; SEASHORE LOUIS, 2012), ou ainda como uma cultura de aprendizagem (LÜCK, 2009) sinalizaram em outra direção, mostrando que gestão escolar é fundamental, entre outras coisas, para o desenvolvimento dos professores no contexto escolar. Neste sentido, o diretor tem de planejar, organizar e conduzir esses processos de formação, juntamente com os outros profissionais que fazem parte da gestão, como é o caso do Coordenador Pedagógico ou Professor Coordenador ${ }^{3}$.

Lück (2009) sinaliza que a capacitação profissional dos professores é constituída por meio de processos sistemáticos e organizados com o objetivo de desenvolver conhecimentos, habilidades e atitudes necessárias para a atuação nas atividades profissionais cuja ação de formação é liderada pelo diretor da escola. Trata-se de um processo que envolve planejamento, estratégias e ações, incluindo, entre outras coisas, a realização de grupos de estudo e oficinas práticas, troca de experiências e de material pedagógico entre os professores e a observação, análise e feedback sobre as experiências profissionais.

Quanto à observação, análise e feedback aos professores, o estudo realizado pela OECD (2013) mostrou que a maior fonte de retorno recebido, quase 90\%, sobre atividade de ensino na escola, estava associada à análise das notas dos alunos, mostrando que muitos diretores realizavam algum tipo de formação de professores no contexto escolar.

3 Na Rede Estadual de São Paulo, esse profissional recebe essa nomenclatura já que se trata de um professor que deixa a sala de aula e passa a exercer a função de professor coordenador.

RIAEE - Revista Ibero-Americana de Estudos em Educação, Araraquara, v.12, n.4, p. 2210-2230, out./dez. 2017. 
Para a formação, no desenvolvimento deste trabalho, o diretor conta, sobretudo, segundo Garrido (2009), com o Horário de Trabalho Pedagógico e Coletivo (HTPC). Mas conta também com a utilização das tecnologias, recursos da Educação a Distância, com a indicação de material, de livros pedagógicos, de cursos, eventos e congressos, dentre outros. A gestão tem, portanto, à sua disposição, um conjunto de elementos para fazer emergir e realizar a formação do professor no contexto escolar.

Grigloli et al, (2010), analisando as características de uma escola de Campo Grande (MS), mostraram como a gestão escolar influencia e potencializa a formação do professor. Os autores trabalharam com a ideia da gestão escolar como mediadora da formação contínua na escola, no entanto, a discussão incidiu apenas de forma superficial sobre as práticas da gestão para conceber e efetivar este trabalho.

Neste sentido, este estudo analisa como a gestão escolar de escolas públicas de ensino fundamental, anos finais, da cidade de maior IDH-M do país (2010), tem idealizado e realizado a formação de professores no contexto escolar. Trata-se de um estudo em um município com altos índices sociais, econômicos e educacionais.

\section{Gestão escolar e formação de professores}

A escola é o local mais apropriado e que mais colabora para o desenvolvimento profissional do professor, considerando que ela se constitui em um espaço real para a construção de conhecimentos e habilidades e, ao mesmo tempo, para o desenvolvimento da identidade profissional.

Canário (1999) sinaliza que a identidade profissional do professor se constrói em seu local de trabalho, por meio de uma formação contínua que considera suas práticas, seus saberes docentes e suas experiências. Afirma também que conceber a formação fora do contexto escolar acaba tornando-a ineficaz, sem um sentido estratégico para as mudanças. Para esse autor, a escola é o lugar decisivo onde as competências adquiridas na formação inicial auxiliam na aquisição e no desenvolvimento de competências profissionais. Desta forma, a otimização das condições de formação e de trabalho tornase o eixo estruturante do percurso formativo.

Esse mesmo autor afirma também que as situações profissionais que os professores experimentam na escola acontecem em um quadro de sistemas coletivos de ação cujas regras são, simultaneamente, produzidas e aprendidas por eles na escola. 
Neste sentido, o autor se refere a um "jogo coletivo" próprio de cada ambiente escolar, que é:

[...] susceptível de múltiplas e contingentes configurações, em função da singularidade dos contextos. É na medida em que a dimensão organizacional atravessa a produção, em contexto, das práticas profissionais que estas não são compreensíveis apenas em termos de efeitos de disposição mas, de um modo muito importante, também em termos de efeitos de situação (os mesmos professores agem de formas diferenciadas, em escolas diferentes). É a impossibilidade de dissociar o "jogo coletivo" da ação de cada individuo que torna impossível, também, dissociar a mudança dos modos individuais de pensar e agir dos processos de mudança organizacional. A mudança da organização de trabalho (ou seja, das escolas) assume então o carácter de um processo coletivo de aprendizagem do qual emergem não apenas novas competências (configurações de saberes) individuais, mas também competências coletivas [...]. (p. 75).

Fusari (2009) sinaliza que a formação contínua em serviço valoriza os professores e auxilia na criação de vínculos com a escola. Para Cunha e Prado (2010), esta formação privilegia a colaboração, a interlocução sobre as práticas, os interesses e as necessidades dos professores. A escola é, portanto, o lócus de formação do professor, pois ela salienta seu contexto de trabalho, suas experiências e práticas, possibilitando a criação de redes colaborativas de formação entre os docentes e entre eles e a gestão escolar.

Neste sentido, a GE, cuja atuação está relacionada à organização, à mobilização e articulação dos processos materiais e humanos da escola, tem de organizar os processos de formação no contexto escolar (LÜCK, 2009), tem de se interessar, planejar, organizar e sistematizar a formação dos professores na escola, tendo em vista que ela é compreendida como "a utilização racional de recursos para a realização de fins determinados" (PARO, 2012, p. 25).

A GE, segundo Lück (2009), se caracteriza pelo ato de gerir a dinâmica cultural da escola, afinado com as diretrizes e políticas educacionais públicas para a implementação de seu projeto político-pedagógico (PPP) e compromissado com os princípios da democracia.

Assim, a GE realiza o planejamento escolar, tornando visível a realidade da escola e as intenções de melhorias, caracterizando-se em um processo contínuo, de responsabilidades compartilhadas, de compromisso com as mudanças, de monitoramento e avaliação dos resultados. Ela atua também na gestão pedagógica, promovendo a elaboração do PPP e seu monitoramento, disseminando a visão do 
trabalho educacional, buscando a melhoria dos processos pedagógicos voltados para a aprendizagem. Neste sentido,

[...] opera na criação de ambiente motivador orientado por elevadas expectativas de aprendizagem, identificando e analisando as limitações e os potenciais das práticas pedagógicas e acompanhando e orientando o processo ensino-aprendizagem na sala de aula (LÜCK, 2009, p. 93).

A gestão escolar também atua no monitoramento e na avaliação escolar. Destaca-se que o monitoramento se constitui no processo de acompanhamento sistemático dos programas e projetos implantados por meio de um plano de ação. Ele tem o intuito de garantir a efetividade do programa, verificando o ritmo de trabalho, incluindo a questão do tempo e dos recursos. Trata-se de um programa contínuo e sistemático para acompanhar os processos da escola. Por sua vez, a avaliação é o processo de medida e de julgamento dos resultados, parciais e finais, obtidos na implantação dos projetos. Com a avaliação verificam-se os objetivos e os fatores que mais contribuíram para explicar os resultados.

A GE atua nos resultados educacionais (GRE), buscando a melhoria do desempenho dos estudantes e da escola em geral. A GRE é tributária do monitoramento e da avaliação, sobretudo com foco nos resultados dos alunos. Trata-se de atuar no rendimento dos estudantes por meio da utilização de vários indicadores, que permitem analisar em relação ao aluno: o desempenho acadêmico (notas nas disciplinas, médias atuais e dos anos anteriores), o índice de absenteísmo, o desenvolvimento social (relacionamento com os colegas, solidariedade, discriminação, grau de colaboração) e atitudinal (respeito ao outro, disciplina, satisfação pela aprendizagem). Quanto ao professor, permite monitorar sua prática pedagógica, o índice de absenteísmo, o interesse pela aprendizagem do estudante, o grau de colaboração, o desenvolvimento profissional, suas expectativas sobre os jovens, o acompanhamento do planejamento de ensino e dos objetivos e sua interação e colaboração com os estudantes.

A GE deve garantir e atuar na formação dos professores no contexto escolar (LUCK, 2009). A formação profissional realizada na escola (em serviço) se refere a um conjunto de atividades planejadas, organizadas, orientadas e mobilizadas pelo diretor, com o intuito de desenvolver, ou levar o professor a adquirir, competências profissionais, que se traduzem por habilidades, conhecimentos e atitudes com o foco na responsabilidade social, na transformação e melhoria das práticas profissionais e da 
escola, na aprendizagem do aluno e no desenvolvimento social. Um processo articulado com o desempenho, monitoramento e avaliação docente.

Para tanto, há a necessidade de, por meio do PPP, possibilitar ao professor meios para que o mesmo possa refletir sobre sua própria prática educativa, problematizando o cotidiano, questionando, transformando o ambiente e sendo transformado (ORSOLON, 2002 apud FRANCO; GONÇALVES, 2013).

Trata-se de um projeto amplo que se inicia no planejamento escolar quando a formação, sob a responsabilidade da equipe gestora, é organizada. A atuação pauta-se, entre outras coisas, nas dificuldades e nas necessidades apresentadas pelo docente no ano anterior e na imprescindibilidade da formação relacionada aos novos projetos que serão desenvolvidos no ano. Ao mesmo tempo, a formação deve incidir sobre os objetivos da escola (ligação com o PPP, criação de altas expectativas) e a avaliação docente, conforme estudo realizado por Grigoli et al, (2010).

Esses autores enfatizaram a atuação da gestão escolar como mediadora da formação contínua dos professores, identificando como processos relevantes de formação sessões de estudo por disciplina e projetos. Ou seja, a utilização de atividades práticas, envolvendo jogos, apresentações e construção de painéis. Tais tarefas visavam o uso desses recursos em sala de aula, levando o docente ao desenvolvimento e domínio de novas habilidades com o intuito de melhorar o aprendizado do aluno e diminuir a repetência. No entanto, o estudo somente tangenciou o conjunto de atividades que podem ser realizadas pela gestão no contexto da formação contínua.

De acordo com Luck (2009, p. 88-89), a formação abarca:

[...] observação, análise e feedback sobre as experiências profissionais e consequente construção de conhecimento, em associação com o conhecimento educacional produzido; realização de grupos de estudo e oficinas práticas sobre aspectos em que se pretende promover mudanças; promoção de troca de experiências e de material pedagógico entre os professores sobre estratégias que utilizam para garantir maior efetividade na aprendizagem dos alunos; estudo sobre competências docentes e de trabalho e fundamentação para o seu exercício consistente; criação de portfólios individuais e por áreas de atuação para os resultados desses estudos e práticas objetivando sua sistematização; planejamento de implementação e incorporação de novas aprendizagens e conhecimentos em novas práticas profissionais.

Este processo envolve também reuniões formativas, individuais ou em grupos por área de conhecimento; algum tipo de aconselhamento pedagógico, onde o diretor ou

RIAEE - Revista Ibero-Americana de Estudos em Educação, Araraquara, v.12, n.4, p. 2210-2230, out./dez. 2017. 
o coordenador acompanha de perto as atividades do professor, observando suas aulas e realizando devolutivas (feedbacks) para a melhoria do trabalho.

Este retorno recebido pelo professor (feedback) pode ser compreendido de forma ampla, incluindo qualquer tipo de diálogo com o profissional sobre sua atuação na escola e na sala de aula. Ele apresenta como fundamento a interação, que pode ocorrer por meio de observação de sala de aula, discussão sobre o planejamento, resultados dos alunos, dentre outros. Trata-se de um processo que pode ocorrer por meio de conversas informais ou de forma estruturada (OECD, 2013).

Os dados do Teaching and Learning International Survey (OECD, 2013) mostraram que $83 \%$ dos professores receberam algum tipo de feedback atrelado à análise das notas dos alunos; $81 \%$ associado à observação direta do ensino em sala de aula; $70 \%$ ligado ao retorno de pesquisas ou discussões com os pais; $67 \%$ relacionado à avaliação do conteúdo; $67 \%$ associado às pesquisas com estudantes sobre o ensino.

O mesmo estudo apontou que, aproximadamente, $80 \%$ dos professores afirmaram que as maiores altas de incidência de feedback estavam relacionadas ao desempenho dos estudantes (76\%); ao conhecimento da área de ensino (69\%) e às habilidades pedagógicas para o ensino (68\%). Neste contexto, 56\% dos profissionais relataram que o retorno recebido proporcionou mudança positiva na sua confiança como professor; $36 \%$ sinalizaram que aumentou a sua motivação; perto de $50 \%$ que houve impacto positivo nas suas responsabilidades de trabalho na escola; $39 \%$ indicaram que ocorreu mudança positiva no conhecimento de sua principal área de ensino e em suas estratégias para ensinar.

Além desta questão dos feedbacks para os professores, para o desenvolvimento do trabalho de formação, o diretor conta com a utilização da tecnologia (recursos da EaD e das mídias sociais), indicação de material e livros pedagógicos, tempo de reuniões, indicação de cursos, eventos e congressos, relatórios formativos, espaços para troca de experiências e grupos de estudo, utilização de profissionais externos à escola (pesquisadores) para a formação dos professores e, sobretudo, do HTPC. Neste sentido, Garrido (2009, p. 11) sinaliza que a formação contínua em serviço deve ocorrer principalmente no HTPC, pois trata-se de um espaço coletivo no qual os docentes podem criar propostas de ensino no sentido de responder às demandas e aos desafios de sua escola e, ao mesmo tempo, serem corresponsáveis por suas formações.

O HTPC, agora conhecido por Atividades de Trabalho Pedagógico Coletivo (ATPC), visa a oportunizar aos professores um tempo em serviço para a sua formação, 
conforme o Inciso V do artigo 13 da Lei de Diretrizes e Bases, Lei 9394/96. Neste sentido, cabe à gestão escolar organizar e sistematizar essa participação, utilizando plenamente o tempo disponível. No entanto, o uso deste espaço não tem representado, de forma clara, um avanço na formação dos professores, no trabalho colaborativo, na transformação das práticas e na melhoria do desempenho dos alunos (MENDES, 2008). Ainda segundo esta autora, para muitos professores as representações do HTPC associam-se às Horas de Tempo Perdido, muitas vezes sem objetivos, com condução inadequada por parte da gestão escolar e ausência de mudanças significativas e duradouras no contexto escolar.

Ainda em relação ao HTPC, Oliveira (2006) sinalizou que os professores não têm, de forma clara, qual a utilidade deste encontro e, neste sentido, sempre que possível eles "fogem" dessas reuniões. Afirmam ainda (os professores) que o espaço acabou se tornando um local para troca de receitas e de pouca formação profissional.

\section{O Contexto da pesquisa}

A cidade investigada, São Caetano do Sul (SCS), é um pequeno município brasileiro, localizado na região metropolitana do estado de São Paulo, em uma região denominada de grande $\mathrm{ABC}$ Paulista.

São Caetano possui uma população de, aproximadamente, 150.000 munícipes (IBGE, 2010) e uma densidade demográfica de 9.342 habitantes/quilômetro quadrado. A cidade tem uma área total pequena, apenas $15,3 \mathrm{~km}^{2}$, quando comparada a outros municípios da realidade brasileira. Obteve a liderança no Índice de Desenvolvimento Humano Municipal (IDH-M) em 2010, com um índice de 0,862; possui uma das maiores rendas per capita do Brasil $(\$ 2.349,00)$ e sua população apresenta mais de 11 anos de estudo.

Esse município apresentava o menor índice de mortalidade infantil no estado de São Paulo, podendo ser comparada aos países desenvolvidos como Alemanha, Áustria, Bélgica e Dinamarca (ÍNDICE FIRJAN DE DESENVOLVIMENTO MUNICIPAL, 2009).

No campo educacional, SCS possuía em 2015, 20 escolas de Ensino Fundamental municipal, três de Ensino Médio, uma de Educação Profissional Técnica e uma de Educação de Jovens e Adultos, com aproximadamente 18.000 alunos matriculados (CENSO ESCOLAR, 2015).

RIAEE - Revista Ibero-Americana de Estudos em Educação, Araraquara, v.12, n.4, p. 2210-2230, out./dez. 2017. 
As escolas (55\%) contavam com acessibilidade para deficientes físicos (rampa e elevadores para mobilidade de cadeirantes) e dispunham de salas de atendimento especial com recursos multifuncionais (70\%). Ademais, todas as salas de aula eram equipadas com lousa eletrônica, computador e projetor (datashow), ligados à internet. Em 2013, os professores receberam da secretaria da educação um computador (tablet) para utilizar nas aulas (GARCIA, 2014). Neste sentido, todas as escolas dispunham de infraestrutura avançada, conforme sugere Soares et al. (2013), que criaram uma escala para medir a infraestrutura das escolas brasileiras.

Em relação ao desempenho das escolas no Índice de Desenvolvimento da Educação Básica (IDEB), Ensino Fundamental, anos finais, o Quadro 01 sintetiza os resultados:

\begin{tabular}{|c|c|c|c|}
\hline \multicolumn{4}{|c|}{ Quadro 01: indicadores de resultados } \\
\hline Ano & Fluxo & Aprendizado & Ideb \\
\hline $\mathbf{2 0 0 9}$ & 86,0 & 6,65 & 5,7 \\
\hline $\mathbf{2 0 1 1}$ & 80,0 & 6,47 & 5,2 \\
\hline $\mathbf{2 0 1 3}$ & 83,0 & 6,33 & 5,3 \\
\hline $\mathbf{2 0 1 5}$ & 91,0 & 6,57 & 6,0 \\
\hline
\end{tabular}

Fonte: Elaboração própria a partir de Dados do Inep (2007, 2009, 2011, 2013 e 2015).

A Tabela indica, como se pode observar, que as escolas, sobretudo a partir de 2011, tiveram um crescimento no IDEB constante e contínuo, atingindo, em 2015, a média seis.

\section{Metodologia}

Este estudo analisa como a gestão escolar de escolas públicas de ensino fundamental, anos finais, da cidade com o maior IDH-M do Brasil, em 2010, idealiza e realiza a formação de professores no contexto escolar.

A cidade foi selecionada por ter elevados índices sociais, econômicos e educacionais, e por estar situada em uma área em pleno desenvolvimento, o grande ABC. Portanto, trata-se de um contexto diferente de outros provenientes do cenário brasileiro, e que pode fornecer pistas para uma compreensão mais profunda de como a gestão escolar idealiza e realiza a formação de professores.

No contexto da pesquisa qualitativa, optou-se pela utilização da abordagem etnográfica, utilizando observação, entrevistas e análise de documentos. Tal situação 
sinaliza, entre outras coisas, a presença do pesquisador no espaço de observação onde ocorrem as situações e interações entre os participantes.

A utilização da etnografia na escola possibilita o aprofundamento para conhecer, entre outras coisas, a origem da escola, o respeito aos regulamentos disciplinares, as concepções e as práticas dos professores, a infraestrutura e a relação com as inovações, a atuação da gestão escolar, sua relação com a comunidade e com a formação de professores.

$\mathrm{Na}$ etnografia, o pesquisador envolve-se com o local e com os grupos. Porém, apesar do envolvimento, ele cria um distanciamento pelo fato de não possuir as mesmas inquietações e preocupações dos indivíduos que fazem parte do contexto. Paralelamente, ele cria familiaridade com a cultura local se relacionando com o outro e com o meio e procurando compreendê-los (CRESWELL, 2014).

Para esse autor, na etnografia, a observação é um procedimento para coletar dados e o pesquisador estuda imerso na realidade, selecionando e interpretando evidências. No entanto, a observação tem de ser sistemática, a partir do uso de protocolos, com controle da duração de tempo e com a realização de registros, que podem incluir falas, citações e gestos. Trata-se de um processo descritivo e reflexivo. A observação utilizada no presente estudo foi estruturada, sistematizada, planejada, controlada e individual. Os observadores se envolveram com as situações e com os eventos de três escolas.

O procedimento de observação aconteceu no ano de 2014, ocorreu uma ou duas vezes por semana em três escolas, durante um ano letivo, e focou nas atuações dos diretores e dos coordenadores pedagógicos (CP). Foram acompanhadas, também, em cada uma dessas escolas, reuniões de planejamento (3), encontros pedagógicos (3), de HTPC (6 no primeiro semestre e 6 no segundo), conselho de classe (1) e atendimentos individuais de professores (8). Além da observação, foram utilizadas entrevistas e análise documental. No primeiro caso, foram entrevistados, além dos três diretores dessas escolas observadas, mais cinco de outras instituições de Ensino Fundamental, anos finais, e, no segundo, analisados os planejamentos escolares (Plano de Ensino, Regimento Escolar, entre outros).

Nas entrevistas, coletaram-se informações sobre: 1) perfil dos participantes em termos de gênero, idade, formação e experiência profissional; 2) como eram idealizados e realizados os processos de formação de professores na escola.

RIAEE - Revista Ibero-Americana de Estudos em Educação, Araraquara, v.12, n.4, p. 2210-2230, out./dez. 2017. 
Os dados das entrevistas foram analisados a partir da teoria fundamentada (CRESWELL, 2002; CORBIN; STRAUSS, 1990), uma abordagem de natureza qualitativa, indutiva, cujos resultados são provenientes das análises realizadas. Os dados deste estudo foram fragmentados com a utilização de uma investigação temática de codificação aberta. A partir disto, eles foram selecionados com o uso de códigos e descritores com o intuito de identificar as diferenças e regularidades, surgindo, a partir desse processo, as categorias do estudo.

Os dados provenientes da documentação escolar foram analisados a partir da análise de conteúdo, com o intuito de se compreender, criticamente, os símbolos, os signos e o sentido das comunicações, ou seja, como cita Chizzotti (2006), o conteúdo manifesto e latente, as significações que são explícitas e outras ocultas.

$\mathrm{Na}$ análise de documentos utiliza-se "um conjunto de técnicas de análise das comunicações, que utiliza procedimentos sistemáticos e objetivos de descrição do conteúdo das mensagens" (BARDIN, 1977). Neste sentido, o uso de documentos traz uma riqueza de informações que podem ser extraídas e analisadas e, desta forma, ampliar a compreensão sobre os fenômenos cuja compreensão necessita de contextualização histórica e sociocultural.

\section{Resultados e discussão}

A maioria dos diretores que tomou parte neste estudo pertencia ao sexo feminino, exceto um. Todos possuíam formação em nível superior, curso de Pedagogia, com média de idade de, aproximadamente, 42 anos, e experiência profissional como diretor de quas 14 anos.

As observações indicaram que os gestores (diretores e CP), em geral, não se consideravam integralmente responsáveis pela formação dos professores no contexto escolar: "nós fazemos algumas atividades para formar o professor, mas os professores têm de capacitar em cursos fora da escola. Isso é interesse deles, tem de melhorar na carreira" (DIRETOR_3). Outro profissional afirmou "com a correria na escola não dá para se preocupar com a formação do professor. Tem o HTPC e lá o coordenador faz o que pode para melhorar, mas tem professor que não quer" (DIRETOR_5).

As equipes de gestão, neste contexto, por se sentirem pouco responsáveis pela formação docente não se preocupavam, diretamente, com a formação de seus profissionais. De fato, no planejamento escolar, não havia nenhuma citação direta que 
indicasse a necessidade de formação para o ano corrente, nem mesmo para os projetos pedagógicos novos. Neste caso, parece que se pressupunha que todos os envolvidos tivessem as habilidades e os conhecimentos necessários para desenvolvê-los.

O planejamento escolar era, geralmente, marcado pela sistematização dos conteúdos que seriam ministrados pelos professores ao longo do ano, pela criação de alguns projetos alusivos ao ano (ano internacional das cooperativas) e pela criação de algumas reuniões informativas, que tratavam, entre outras coisas, da organização e da disciplina escolar. Não existiam referências que indicassem formação docente.

De fato, nas análises dos documentos escolares não foram encontradas evidências de que era uma preocupação direta da gestão escolar, diretores e CP, a formação de professores. Havia somente no regimento escolar algumas poucas indicações para os CP, não para os diretores, dissipadas em suas tarefas gerais para formação docente. Entre elas: "propor e coordenar atividades de aperfeiçoamento e atualização de professores" (REGIMENTO ESCOLAR, 2011, p. 09). Situação análoga com o que ocorre em Santa Maria (RS), conforme estudo realizado por Sagrillo; Pereira; Zientarski (2013, p. 1052). Segundo essas autoras,

[...] ao se analisar o Projeto Político-Pedagógico (PPP), cuja relevância é indiscutível, constatou-se que a formação continuada da escola investigada aparece apenas diluída no texto, às vezes de forma indireta. Não há um item específico que trate da formação dos professores.

Ainda de acordo com as autoras, consta desse documento que cabe à "direção [da escola] oportunizar um constante aperfeiçoamento do corpo docente e da equipe coordenadora e à [...] vice-direção promover e participar de reuniões, sessões de estudos, encontros, palestras, seminários e outros" (SANTA MARIA, 2007, p. 20-21).

Embora a formação docente não esteja institucionalizada no planejamento, PPP e no regimento escolar, não significa que ela não ocorra. Em SCS, as ações formativas para os docentes aconteciam ao longo do ano nas escolas sob a liderança da equipe gestora. Não obstante, observou-se que, na maioria das vezes, no cotidiano escolar, os $\mathrm{CP}$, muitos mais do que os diretores, eram os profissionais que atuavam de modo mais efetivo na formação docente, cabendo aos diretores realizar o alinhamento e monitoramento da ação.

Depreende-se, portanto que, já que o CP assume para si a maior responsabilidade pela formação, há necessidade de ele:

RIAEE - Revista Ibero-Americana de Estudos em Educação, Araraquara, v.12, n.4, p. 2210-2230, out./dez. 2017. 
[...] ser o agente direcionador da formação, já que seu trabalho precisa se desenvolver na busca de caminhos que solucionem/minimizem as dificuldades presentes na escola em conjunto com os demais atores sociais, na busca de uma educação transformadora/emancipatória, visando sempre o aprendizado do educando (FRANCO; GONÇALVES, 2013, p. 65).

No entanto, embora exista a sinalização para o $\mathrm{CP}$ atuar de forma mais direta na formação docente, isso não isenta o diretor dessa responsabilidade já que "quer pela legislação e pelos órgãos superiores do sistema, quer pelas pessoas que com ele convive no cotidiano escolar, o diretor é visto como o responsável último pela escola" (PARO, 2011, p. 42).

Nas escolas investigadas, a tarefa de formação dos professores estava mais atrelada ao trabalho dos coordenadores pedagógicos. Somente um diretor participava desses eventos. Tal situação demonstra, em geral, o desinteresse e a falta de entendimento, dos diretores, da importância da formação do professor no contexto escolar. Em apenas em uma escola, onde havia a participação do diretor no HTPC, as análises mostraram verdadeiros indícios da construção de uma cultura reflexiva.

Nessas escolas, em geral, observou-se que a formação docente ocorria de várias formas: conversas informais no início do período sobre as notas de um aluno, conversas formais sobre algum tipo de reclamação dos pais, indicação de textos para leitura, reprodução de vídeos sobre a aprendizagem do aluno, dentre outros. Era um trabalho realizado sem um planejamento organizado, objetivos direcionados e sistematização dos processos.

Neste contexto, o principal espaço de formação na escola era constituído pelo HTPC. Em todas as escolas, exceto uma, nos momentos de HTPC, o tempo era quase todo dedicado às questões administrativas. Tratava-se de uma seção de conversas, recados e avisos gerais e particulares (data para a entrega de notas para secretaria, realizar a chamada no início da aula, alunos com faltas excessivas, disciplina de uma classe específica, dentre outros). Algumas vezes aconteciam trocas de experiências pedagógicas, reprodução de algum vídeo educativo ou discussão de textos pedagógicos, mas esses ocorriam de forma episódica. Assim, como afirmam Sagrillo, Pereira e Zientarski (2013, p. 1052),

[...] a prioridade das horas-atividades se reduz a reuniões informativas, mais de caráter técnico-burocrático do que de estudos que diagnostiquem os reais problemas da escola com vistas a um 
aprofundamento dos referenciais teóricos que deem suporte ao conjunto da comunidade escolar no sentido de buscar alternativas para uma melhoria dos resultados escolares.

De fato, como sinalizou um coordenador "são tantas coisas que precisam ser tratadas no HTPC que muitas vezes não sobra tempo para falar do pedagógico ou das dificuldades de aprendizagem dos alunos" (CP_5). Outra profissional indicou sua falta de conhecimento no trabalho de formação dos professores afirmando que "não tenho conhecimento de todas as disciplinas e assim não tenho condições de atuar com os conteúdos dos professores, tento fazer o que dá" (CP_3).

Dada a realidade da escola pública, de certo modo, é compreensível as falas da $\mathrm{CP}$, mas considerando-se que o HTPC deveria ser voltado para a formação docente e que, em geral, eles almejam "uma formação prática, ligada ao trabalho, que parte dos problemas concretos e permite resolvê-los proporcionando-lhes um benefício tangível" (DUBAR, 1997, p. 49 apud MACHADO; FORMOSINHO, 2009, p. 288), é imprescindível que a equipe gestora, incluindo os CP, repense o HTPC dessa escola, pois uma "formação válida é a que desenvolve saberes práticos, úteis para o trabalho e adquiridos directamente (sic) pelo seu exercício" sendo esse espaço fundamental para dar conta dessa demanda.

Para muitos $\mathrm{CP}$, esses encontros não são valorizados pelos professores, pois os dias da semana que acontecem as reuniões são aqueles que docentes mais faltam ou abonam (ausência justificada por lei): "o dia do encontro é o dia que alguns professores mais faltam. Parece que eles não gostam do HTPC. Tá certo que algumas vezes o encontro é mais burocrático do que pedagógico" (CP_11). De fato, o estudo de Mendes (2008) mostrou que muitos professores concebem o encontro do HTPC como Horas de Tempo Perdido Coletivo. Neste caso, indicando que o encontro não colabora com suas formações e não tem alcançado seus objetivos de promover mudanças significativas, o que é também indicado por Oliveira (2006), que mostrou que os docentes não estão certos da verdadeira utilidade deste espaço.

Mas, em uma escola, o HTPC era sempre constituído de discussões pedagógicas que envolviam: os projetos realizados, focando nos avanços e nas necessidades; as aprendizagens dos alunos, procurando compreender as dificuldades dos jovens e as possibilidades de auxiliá-los; as práticas dos professores, neste caso aconteciam debates sobre uma estratégia de ensino apresentada; as práticas da coordenação, os professores

RIAEE - Revista Ibero-Americana de Estudos em Educação, Araraquara, v.12, n.4, p. 2210-2230, out./dez. 2017. 
praticamente realizavam uma análise do trabalho da $\mathrm{CP}$; a colaboração, os profissionais atuavam e se responsabilizavam juntos pelo sucesso dos alunos.

Nesta escola, o diretor atuava diretamente no HTPC e pelo menos duas vezes no semestre havia algum tipo de curso realizado na escola em parceria com alguma universidade. Também havia grupos de estudo entre gestão e docentes e as devolutivas dadas aos professores aconteciam diariamente. Um docente recebia, em média, dois feedbacks sobre seu trabalho com os alunos ao mês.

Nesta mesma escola, ocorria, pelo menos uma vez a cada seis meses, troca de experiências entre os pares sobre as práticas dos professores realizadas em sala. Quando um professor tinha algum tipo de atividade ou aula que considerava inovadora, a CP realizava manobras (colocava estagiárias na sala) para que a aula fosse assistida pelos outros professores. Após o encontro, ainda na mesma semana, acontecia um debate entre os docentes e a coordenação sobre a aula realizada.

Ademais, nesta escola, a gestão utilizava-se dos recursos da Educação a Distância para auxiliar a formação docente. Era utilizado um ambiente de aprendizagem (Moodle) no qual todos os professores estavam cadastrados para que ocorressem discussões sobre textos e situações-problemas reais da escola. Os gestores utilizavam também as redes sociais, neste caso, possuíam um grupo no WhatsApp, onde informações sobre o campo profissional eram discutidas. Embora não houvesse sinalização desta realização no planejamento escolar e nos objetivos da escola, indicando que mesma nesta instituição tratava-se de uma formação ainda em formação. Nesse caso, como no estudo realizado por Grigoli et al (2010, p.249), observa-se que para a equipe gestora "o objetivo é que os professores desenvolvam e dominem novos procedimentos para melhorar o aprendizado do aluno, evitando a repetência, o que acaba resultando na boa qualidade do ensino na escola".

Não obstante, nas outras instituições não foram identificados diretores que participavam dos encontros de HTPC. A sinalização de um deles atrelava-se ao fato de que "existem tantas coisas para se dar conta que deixo a parte pedagógica para a coordenadora e acho que é mesmo de sua responsabilidade, sabe, HTPC, etc." (DIRETOR_3). No entanto, uma coordenadora admitiu que "é mais difícil trabalhar com os professores e muitos diretores preferem ficar fora deste serviço" (CP_5).

Em algumas escolas (4), os CP realizavam a indicação de livros e textos para seus professores. Nesses dois casos, o livro e o texto indicados tinham natureza pedagógica. Mas eles não tinham sido indicados para que o professor pudesse avançar 
em seus conhecimentos e melhorar sua prática pedagógica. A indicação, geralmente acontecia por se tratar de um material que o $\mathrm{CP}$ considerava relevante e, desta forma, indicava para os profissionais lerem. Como sinalizou uma coordenadora "eu faço indicações para eles se manterem atualizados de forma geral. Não é específico da sala de aula" (CP_4).

Em todas as escolas aconteciam reuniões individuais entre o CP (ou o diretor) e o professor. Neste contexto, aconteciam feedbacks da gestão escolar sobre o trabalho do professor. As devolutivas mais comuns estavam relacionadas às questões das notas dos alunos (100\%), à indisciplina na sala de aula (83\%), às reclamações de pais $(83 \%)$, à postura do professor (discussão com aluno em sala, uso de linguagem inadequada) (67\%) e, algumas vezes, à observação do ensino do professor (33\%). No entanto, essas devolutivas não eram sistemáticas e planejadas, e aconteciam no desencadeamento de novas ações, ou seja, quando algum fato novo ocorria na escola (notas baixas dos alunos, reclamações dos pais).

O dado que chama a atenção se refere ao retorno realizado pela gestão (diretor ou $\mathrm{CP}$ ) relacionado à observação da aula do professor. Enquanto neste estudo internacional (OECD, 2013), os dados brasileiros indicavam que esta atividade era realizada por $81 \%$ dos diretores, nas escolas investigadas da cidade de maior IDH-M do Brasil, somente $33 \%$ dos diretores realizavam tal tarefa, com predominância descritiva nos feedbacks. Trata-se, portanto, de uma situação que indica discordância de resultados, muito provavelmente relacionada às amostras dos estudos.

Neste contexto, ainda embrionário de formação de professores na escola, as reuniões de devolutivas entre a gestão e o professor aconteciam tendo como principal fonte de discussão as questões das notas dos alunos, indicando similaridade com os dados nacionais da pesquisa internacional realizada pela Organização para a Cooperação e Desenvolvimento Económico (OECD, 2013). Outros temas muito tratados nos encontros entre gestão e professores estavam atrelados à indisciplina e às reclamações de pais. Observa-se, neste cenário, o distanciamento das questões reflexivas relacionadas à aprendizagem e ao desempenho dos alunos, entre outros.

Os feedbacks recebidos apresentavam diversas formas. Alguns deles eram descritivos e se relatava ao professor o acontecido para que ele apresentasse sua versão para aquele fato e, desta forma, eram realizados indicativos para a solução do problema. Em alguns casos tratava-se da culpabilização do professor pelas notas baixas dos alunos e somente em poucos casos, a devolutiva, de fato, era reflexiva e pedagógica.

RIAEE - Revista Ibero-Americana de Estudos em Educação, Araraquara, v.12, n.4, p. 2210-2230, out./dez. 2017. 
Alguns CP (2) indicavam cursos ou congressos para seus professores. Esses eventos algumas vezes eram sugeridos pela Secretaria de Educação e repassados para os professores; outras vezes eram selecionados pelos coordenadores. No entanto, eles não tinham relação direta com uma necessidade do professor ou com uma aprendizagem especial para o desenvolvimento de um projeto escolar: "indico cursos, congressos para eles porque assim eles podem voltar a estudar. Nem sempre esses cursos são bons ou são o que eles precisam, mas ajuda, sabe" (CP_8).

A formação dos professores das escolas analisadas era toda realizada no Centro de Formação de professores da cidade, local onde aconteciam cursos, oficinas, congressos, dentre outros eventos. De fato, todos os diretores e $\mathrm{CP}$, exceto um diretor e um CP, acreditavam que o melhor espaço para formação era o Centro, pois lá os profissionais eram preparados para realizar este tipo de trabalho. Como sinalizou uma coordenadora "o local ideal para formação é o Centro de Formação, pois lá eles têm profissionais habilitados, espaços e materiais para o trabalho" (CP_6). A escola, para outro, era um "local onde tudo acontece e não se tem tempo para estudar ou preparar algum tipo de formação" (CP_2).

Vale destacar que os profissionais da gestão escolar que foram entrevistados neste estudo, não se sentiam, de fato, responsáveis pela formação dos professores, embora eles realizassem várias atividades neste sentido de forma não sistematizada e organizada. Desta forma, apesar de a literatura sinalizar que a formação dos professores deve acontecer, sobretudo no contexto escolar (CANÁRIO, 1998; FUSARI, 2009; GARCIA, 2010; CUNHA; PRADO, 2010; FULLAN, 2000; LÜCK, 2009), tal situação foi encontrada nas escolas investigadas apenas de forma indireta, mas não organizada e sistematizada, atrelada aos objetivos da escola. A formação acontecia, prioritariamente, no Centro de Formação de professores da cidade, retirando a escola do locus da formação, e, como sinalizou Canário (1998) “a maneira descontextualizada de conceber a formação profissional é a principal responsável pela sua ineficácia”, pois é impossível separar o "jogo coletivo" da atuação de cada professor. As inovações e mudanças requeridas na escola necessitam de um processo coletivo de aprendizagem.

Por fim, relata-se que as evidências encontradas neste estudo ampliam os achados da pesquisa de Grigoli et al, (2010), trazendo maiores informações sobre atividades de formação contínua realizadas pela gestão escolar e acontecidas no contexto escolar. 


\section{Considerações finais}

Este estudo revelou como a gestão escolar de escolas públicas de ensino fundamental, anos finais, da cidade com o maior IDH-M do Brasil em 2010 (São Caetano do Sul), idealiza e realiza a formação de professores.

Os dados deste estudo apontam na direção de que as escolas realizavam algum tipo de formação contínua de professores no contexto escolar. No entanto, acontecia o que podemos denominar de uma formação "selvagem” (embrionária e não controlada), marcada pela ausência de planejamento, de organização, de sistematização, de objetivos e de compromissos com o desenvolvimento profissional docente; pela utilização do principal espaço de formação, o HTPC, em momentos muito mais informativos do que formativos; por reuniões individuais entre gestão e professores (feedbacks) que não eram planejadas e nem sistematizadas e acabavam acontecendo, geralmente, na urgência e na incerteza da obtenção de resultados positivos, e, por fim, pela descontextualização da formação profissional, retirando seu lócus da escola e situando no Centro de Formação da cidade.

Todas essas questões situadas eram decorrentes do fato de a gestão escolar não se sentir integralmente responsável pela formação dos professores, e, ao mesmo tempo, pela falta de formação dos próprios gestores escolares e pela ausência de um projeto da rede municipal de educação para instituir e conduzir a formação no contexto escolar.

\section{REFERÊNCIAS}

BARDIN, L. Análise de conteúdo. Lisboa: Edições 70. 1977.

CANÁRIO, R. O Professor entre a Reforma e a Inovação. Organização e Gestão da Escola. Univesp. p. 66-83, 1999.

CHIZZOTTI, A. Pesquisa em ciências humanas e sociais. 8a ed. São Paulo: Cortez. 2006.

CORBIN, J.; STRAUSS, A. Basics of qualitative research: techniques and procedures for developing grounded theory. 2 ed. London: Sage Publications. 1998.

CRESWELL, J. Educational Research: Planning, Conducting, and Evaluating Quantitative and Qualitative Research. New Jersey: Merrill Prentice Hall. 2005.

CRESWELL, J. Investigação qualitativa e projeto de pesquisa: escolhendo entre cinco abordagens. Trad. Sandra Mallmann da Rosa; Revisão Técnica Dirceu da Silva. 3. ed. Porto: Penso, 2014.

RIAEE - Revista Ibero-Americana de Estudos em Educação, Araraquara, v.12, n.4, p. 2210-2230, out./dez. 2017. 
CUNHA, R. C. O. B.; PRADO, G.V.T. Formação centrada na escola, desenvolvimento pessoal e profissional de professores. Revista de Educação PUC - Campinas, n. 28, p. 103-113, 2010.

DUFOUR, R.; MARZANO, R. High-leverage strategies for principals leadership?

Educational Leadership, v. 66, n. 5, p. 62-68, 2009.

DUFOUR, R.; FULLAN, M. Built to last: Systemic PLCs at work. Bloomington. 2013.

FRANCO, M. J. N.; GONÇALVES, L. S. M. Coordenação pedagógica e formação de professores: caminhos de emancipação ou dependência profissional. Psicol. da Educ., São Paulo, 37, 2013, pp. 63-71.

FULLAN, M. All Systems go. Thousand Oaks, CA: Corwin Press. 2010.

FULLAN, M. The Principal: Three keys to maximizing impact. San Francisco: Jossey-Bass, 2014.

FULLAN, M.; HARGREAVES, A. A escola como organização aprendente: buscando uma educação de qualidade. Porto Alegre: Artmed, 2000.

FUSARI, J. C. Formação contínua de educadores na escola e em outras situações. In: BRUNO, E. B. G.; ALMEIDA, L. R.; CHRISTOV, L. H. S. (Org). O coordenador pedagógico e a formação docente. 3. Ed, São Paulo: Loyola, 2009, p. 17-24.

GARCIA, P. S. Inovações e mudanças: por que elas não acontecem nas escolas? Uma macroanálise envolvendo professores de ciências. 1. ed. São Paulo: LCTE Editora, 2010.

GARCIA, P. S. Um estudo de caso analisando a infraestrutura das escolas de ensino fundamental. Cadernos de Pesquisa: pensamento educacional. Curitiba: Online, v. 9, p. 153-175, 2014.

GARRIDO. E. Espaço de formação continuada para professor coordenador. In: BRUNO, E. B. G.; ALMEIDA, L. R.; CHRISTOV, L. H. S. (Org.). O coordenador pedagógico e a formação docente. 10 ed. São Paulo: Loyola, 2009, p. 09-15.

GRIGOLI, J. A. G.; et al. A escola como lócus de formação docente: uma gestão bemsucedida. Cad. Pesquisa, v. 40, n. 139, p. 237-256, 2010.

LEITHWOOD, K.; SEASHORE LOUIS, K. Linking leadership to student learning. San Francisco, CA: Jossey-Bass.

LIBÂNEO, J. C.; OLIVEIRA, J. F.; TOSCHI, M. S. Educação escolar: políticas, estrutura e organização. São Paulo: Cortez, 2007.

LÜCK, H. Dimensões da gestão escolar e suas competências. Curitiba: Editora Positivo, 2009. 
MACHADO, J.; FORMOSINHO, J. Professores, escola e formação. Política e práticas de formação contínua. In.: FORMOSINHO, J. (Org.) Formação de professores: aprendizagem profissional e acção docente. Porto Editora, 2009, p.287-302.

MENDES, C. C. T. HTPC: hora de trabalho perdida coletivamente? 2008, 113p. Dissertação (Mestrado). Faculdade de Educação, Universidade Paulista Júlio de Mesquita Filho, Presidente Prudente/SP, 200.

ÍNDICE FIRJAN DE DESENVOLVIMENTO MUNICIPAL. Relatório Técnico. Disponível em: <http://www.firjan.org.br/ifdm/>. Acesso em: 19 nov. 2016.

\section{ORGANIZATION FOR ECONOMIC COOPERATION AND DEVELOPMENT.}

TALIS 2013: Technical Report. OECD Publishing. Paris.

OLIVEIRA, N. A. R. DE. A HTPC como espaço de formação: uma possibilidade. Dissertação (Mestrado). Linguística Aplicada e Estudos da Linguagem. Pontifícia Universidade Católica de São Paulo. São Paulo, 2006.

PARENTE, J. M. Gerencialismo e performatividade na gestão educacional do estado de São Paulo. Tese (Doutorado em Educação) apresentada à Faculdade de Ciências e Tecnologias da Unesp, Presidente Prudente (SP), 2016. 134p.

PARO, V. H. Administração Escolar: introdução crítica. 17. ed. revista e ampliada. São Paulo: Cortez, 2012.

PARO, V. H. Crítica da estrutura da escola. São Paulo: Cortez, 2011.

RAMOS, G. P. Racionalidade e gerencialismo na política educacional paulista de 1995 a 2014: muito além das conjunturas. Ensaio, v. 24, n. 92, 2016.

SECRETARIA DE EDUCAÇÃO DE SÃO CAETANO DO SUL. Regimento Escolar, n 1, p. 44, 2011.

SAGRILLO, D. R.; PEREIRA, S. M., ZIENTARSKI, C. O espaço da escola na formação continuada de professores: lócus de conquista ou mera formalidade? Perspectiva, Florianópolis, v. 30, n. 3, 1045-1072, set./dez. 2012.

\section{Como referenciar este artigo}

GARCIA, Paulo Sergio.; MIRANDA, Nonato Assis de. A gestão escolar e a formação docente: um estudo em escolas de um município paulista. Revista Ibero-Americana de Estudos em Educação, Araraquara, v. 12, n. 4, p. 2210-2230, out./dez. 2017. Disponível em: <http://dx.doi.org/10.21723/riaee.v12.n4.out./dez.2017.9283>. E-ISSN: 1982-5587.

Submetido em: 26/01/2017

Aceito em: 02/07/2017

RIAEE - Revista Ibero-Americana de Estudos em Educação, Araraquara, v.12, n.4, p. 2210-2230, out./dez. 2017. 